Reprod. Nutr. Dévelop., 1983, 23 (1), 41-50.

\title{
Flow-dependent transfer of antipyrine in the human placenta in vitro
}

\author{
J. C. CHALLIER (1), Ph. D'ATHIS (*), M. GUERRE-MILLO, \\ M. NANDAKUMARAN
}

Laboratoire de Biologie de la Reproduction, Université Pierre et Marie Curie, Paris, France.

$\left.{ }^{*}\right)$ Laboratoire de Pharmacologie biochimique,

Hôpital St-Vincent-de-Paul, Paris, France.

Summary. Placental transfer of antipyrine, a small liposoluble molecule, was investigated at varying flow rates using dual perfusion of human placental lobules. With a flow ratio equal to unity, the fœtal transport fraction (fœetal vein concentration $\times 100 /$ maternal artery concentration) of antipyrine averaged 0.33 . It has been suggested that effectiveness of exchange in the lobule perfused in vitro approximated that of a concurrent model with an antipyrine ' $\mathrm{d}$ ' coefficient between 0.6 and 1.2, including shunting which diverted 16 p. 100 of fœtal and 13 p. 100 of maternal flow rates from the exchange area. These observations have been discussed in relation to data obtained in other mammalian placentas and in man in vivo.

\section{Introduction.}

The transfer of highly liposoluble and uncharged molecules across vascularized biological membranes depends mainly on arterial concentration and blood flow rate. The disposition of blood streams also intervenes when the membrane is interposed between two circulations, as in the case of the placenta. In some typical blood stream arrangements, a specific relationship exists between transfer and flow rate (Bartels and Moll, 1964 ; Meschia et al., 1967). Thus, crosscurrent and countercurrent exchangers have been ascribed to sheep (Rankin and Peterson, 1969) and to guinea-pig (Moll and Kastendieck, 1977) placentas, respectively.

Although numerous studies in man have been devoted to placental circulation, the arrangement of fotal and maternal bloodstreams in vivo is still not well defined. On the other hand, change in molecule transfer with variations in flow rate has received little attention. Using the relationship between the transfer of a highly diffusible molecule (antipyrine) and the flow rates of

(1) Reprint request : J. C. Challier, Laboratoire de Biologie de la Reproduction, Université Pierre et Marie Curie, Bt A, $7^{e}$ étage, 7, quai St-Bernard, 75230 Paris Cedex 05. 
perfusion fluid as a point of departure, we have attempted to define the type of arrangement in the human placenta perfused in vitro.

The results were expressed according to parameters developed by Faber and Hart (1966) and Faber (1969) which is one of the simplest ways of describing steady-state materno-fœtal and fœto-maternal transfers in relation to flow rate. They were analyzed using the equations of certain ideal heat exchangers adapted to the placental situation.

The perfusion of the human placental lobule is suitable for this kind of study. Flow rates can be changed within desired limits and flow rates and transfer can be measured with reasonable accuracy.

The relationship between transfer and flow rate permits the effectiveness of the human placenta to be compared to that of other mammalian placentas. This study also allowed us to estimate antipyrine clearance in vivo.

\section{Material and methods.}

1. Perfusion. - The perfusion method we used has been described by Schneider, Panigel and Dancis (1972). It consists of simultaneously perfusing the two circulations of a suitable lobule in open circuit. We used Earle's buffered solution for perfusion $\left(\mathrm{NaCl}: 6.8 ; \mathrm{KCl}: 0.4 ; \mathrm{NaH}_{2} \mathrm{PO}_{4}, \mathrm{H}_{2} \mathrm{O}: 0.125 ; \mathrm{MgSO}_{4}, 7 \mathrm{H}_{2} \mathrm{O}\right.$ : $0.2 ; \mathrm{NaHCO}_{3}: 1.54 ; \mathrm{CaCl}_{2}: 0.2 ; \mathrm{D}$-glucose $: 1.5 \mathrm{~g} / \mathrm{ll}$ equilibrated with a gas mixture containing 95 p. $100 \mathrm{O}_{2}+5$ p. $100 \mathrm{CO}_{2}$ or 95 p. 100 air +5 p. $100 \mathrm{CO}_{2}$.

The antipyrine transfer from mother to fœtus and from fœtus to mother was measured with ${ }^{14} \mathrm{C}$-antipyrine (NEN, $10-20 \mathrm{mCi} / \mathrm{mM}$ ) or ${ }^{3} \mathrm{H}$-antipyrine (NEN, 100$200 \mathrm{mCi} / \mathrm{mM}$ ) in two separate series of experiments. Labelled antipyrine was added to the maternal or the fœtal perfusion medium depending on the study. Non-labelled antipyrine $(10 \mathrm{mg} / \mathrm{ml})$ was also added with the radioactive material.

2. Measurement. - Two variables were studied: antipyrine transfer and perfusion flow rate. To measure antipyrine transfer, venous perfusate samples were collected from the foetal circuit at various intervals of perfusion time when transfer was from the maternal to the foetal side, and from the maternal circuit when transfer was in the reverse direction.

The antipyrine in these samples, along with that in arterial perfusate samples, was separated by serial chloroform extraction. After evaporation of the chloroform phase, the residue which contained at least $93 \mathrm{p} .100$ of the antipyrine content of the sample, was counted in diotol in a Packard scintillation spectrometer. The ratio of $\mathrm{cpm} / \mathrm{ml}$ in the venous perfusate to that in the arterial perfusate gave the fraction of the substance transferred from one circuit to the other. We used fœetal transport fraction $T_{F}=\left(C_{F_{V}} / C_{M a}\right) \times 100$ to study antipyrine transfer from the maternal to the fœtal side, and maternal transport fraction $T_{M}=\left(C_{\mathrm{Mv}} / \mathrm{C}_{\mathrm{Fa}}\right) \times 100$ when antipyrine transfer was from the fœetal to the maternal side. $T$ represented the transport fraction (in p. 100), $C$ the $\mathrm{cpm} / \mathrm{ml}$ of radioactive material in the perfusion medium, $M$ and $F$ the maternal and fœtal perfusion circuits, and a and $v$ the artery and vein.

Flow rates were measured with Brooks $R 215 \mathrm{~A}$ flowmeters at the arterial and venous ends of the fotal circuit. A single flowmeter measured the flow rate 
in the maternal arterial circuit. The flow ratio $R$ was calculated by dividing fœtal flow rate $\left(Q_{F}\right)$ by maternal flow rate $\left(Q_{M}\right)$. A flow ratio equal to unity was obtained for flow rates around $10 \mathrm{ml} / \mathrm{min}$. Low flow ratios were obtained by lowering the fotal flow rate and high flow ratios by decreasing the maternal one. The perfusion pressure was kept under $40 \mathrm{~mm} \mathrm{Hg}$ in the fotal circuit and under $90 \mathrm{~mm} \mathrm{Hg}$ in the maternal one.

3. Data analysis. - Transport fraction and related flow ratio were measured in 20 experiments. $T_{M}$ and $T_{F}$ values were grouped according to their flow ratio $R$ into cells ranging from 0 to 7.23 and with a width of 0.15 . Only maximal $T_{M}$ and $T_{F}$ values were retained for calculation within each flow ratio cell. This permitted us to eliminate the low transport fractions resulting from incorrect superposition of maternal and foetal circulations.

4. Comparison of ideal exchangers. - We used concurrent, countercurrent and crosscurrent models. For concurrent and countercurrent exchangers, respectively, (Faber, 1969), the following equations were employed:

$$
\begin{aligned}
T_{M} & =\frac{R(E-1)}{E(R+1)} \quad \text { where } E=\exp \frac{d(R+1)}{R} \\
T_{M} & =\frac{R(E-1)}{(R . E)-1} \quad \text { where } E=\exp \frac{d(R-1)}{R} .
\end{aligned}
$$

For the crosscurrent exchanger (Moll and Kastendiek, 1977), we used :

$$
\mathrm{T}_{\mathrm{M}}=\frac{1}{\mathrm{R}}\left(1-\exp \left(-\mathrm{R}\left(1-\exp -\frac{\mathrm{d}}{\mathrm{R}}\right)\right)\right) \text {. }
$$

$T_{M}$ and $R$ have been defined before. $d$ was a dimensionless coefficient obtained by dividing permeability $P$ (number of millimoles transferred per unit of time, per unit of concentration difference, $\mathrm{ml} / \mathrm{min}$ ) by the product of flow rate $Q$ $(\mathrm{ml} / \mathrm{min})$ and the ratio of the concentration of the physically dissolved solute and its total concentration in the perfusion medium. This latter ratio equalled unity for antipyrine in Earle's solution.

With the above equations we calculated $d_{M}$ from $T_{M}$ and $R$. $d_{F}$ was computed from $T_{M}$ and $R$, assuming that $T_{M}=R T_{F}$. A previous report (Challier et al., 1977) has proved this assumption to be valid for transfer as well as for exchange in the human placental lobule perfused in vitro.

The effect of shunting was taken into account when using $T_{M}^{\prime}=R T_{F}\left(1-S_{F}\right)$ and $T_{M}^{\prime \prime}=T_{M}\left(1-S_{M}\right)$, respectively, instead of $T_{M}$, to calculate $d_{F}$ and $d_{M}$ in the above equations. Two situations were considered : the finite value and the infinite value of $d$.

5. Computing methods. - The permeability coefficients $d_{F}$ and $d_{M}$ and the extent of shunting $S_{F}$ and $S_{M}$ were estimated by the non-linear least-squares method using a Gauss-Newton-type algorithm.

The fit of our experimental values to the theoretical models was evaluated by the linear regression : measured value $=a+b$. theoretical value. Best adjustment was considered for $a=0, b=1$ with a correlation coefficient $r=1$. Three 
parameters were used to estimate the fit : the value of $r$, the values of ' $a$ ' and ' $b$ ', and Student's t-test for ' $a$ ' and ' $b$ '.

\section{Results.}

Antipyrine transport fractions from mother to fœetus and from fœtus to mother were measured at flow ratios ranging from 0.08 to 7.23 . The results are presented in table 1.

TABLE 1

Antipyrine transfer from mother to foetus and from foetus to mother.

\begin{tabular}{|c|c|c|c|c|c|}
\hline Cells of $R$. & $\mathrm{R}$ & $\mathrm{O}_{\mathrm{F}}$ & $\mathrm{O}_{M}$ & $T_{F}$ & $T_{M}$ \\
\hline $0-.15$ & 0.08 & 0.10 & 12.0 & 67 & \multirow{6}{*}{19} \\
\hline \multirow{2}{*}{$\begin{array}{c}0-.15 \\
0.15-.30\end{array}$} & 0.21 & 2.6 & 12.5 & 68 & \\
\hline & 0.21 & 3.2 & 15.0 & & \\
\hline $0.30-.45$ & 0.35 & 3.5 & 10.0 & 58 & \\
\hline $0.45-.60$ & 0.47 & 5.6 & 12.0 & 51 & \\
\hline \multirow[t]{2}{*}{$0.60-.75$} & 0.60 & 5.5 & 9.1 & 49 & \\
\hline & 0.72 & 4.4 & 6.1 & & \multirow[t]{2}{*}{27} \\
\hline \multirow[t]{2}{*}{$0.75-.90$} & 0.86 & 8.6 & 10.0 & 43 & \\
\hline & 0.86 & 16.8 & 19.6 & & \multirow[t]{7}{*}{34} \\
\hline $0.90-1.05$ & 1.03 & 6.0 & 5.8 & 43 & \\
\hline $1.20-1.35$ & 1.34 & 7.8 & 5.8 & 33 & \\
\hline $1.35-1.50$ & 1.38 & 9.7 & 7.0 & 26 & \\
\hline $1.50-1.65$ & 1.51 & 11.8 & 7.8 & 22 & \\
\hline $1.65-1.80$ & 1.69 & 12.0 & 7.1 & 22 & \\
\hline $2.10-2.25$ & 2.22 & 10.0 & 4.5 & 21 & \\
\hline $2.25-2.40$ & 2.31 & 9.0 & 3.9 & & \multirow[t]{3}{*}{37} \\
\hline $2.55-2.70$ & 2.63 & 9.2 & 3.5 & 16.5 & \\
\hline \multirow{2}{*}{$2.70-2.85$} & 2.73 & 9.6 & 3.5 & 17 & \\
\hline & 2.81 & 9.0 & 3.2 & & \multirow[t]{2}{*}{35} \\
\hline $2.85-3.00$ & 2.88 & 9.8 & 3.4 & 19 & \\
\hline$>3.00$ & 6.48 & 18.8 & 2.9 & & 42 \\
\hline$>3.00$ & 7.23 & 18.8 & 2.6 & & 40 \\
\hline
\end{tabular}

Maximal transport fraction in each cell of $R$ (size : 0.15 to 3.00 ) is shown. $R$ is the ratio of foetal $\left(Q_{F}\right)$ and maternal $\left(Q_{M}\right)$ absolute flow rates $\left(\mathrm{ml} / \mathrm{min}\right.$.). $T_{F}$ and $T_{M}$ represent the foetal transport fraction (foetal venous/maternal arterial concentrations $\times 100$ ) and the maternal transport fraction (maternal venous/foetal arterial concentrations $\times 100$ ) of antipyrine respectively.

Transport fractions were plotted against flow ratios (fig. 1). At flow ratios down to 1.8 , a direct relationship between $T_{M}$ and $R$ and an inverse relationship between $T_{F}$ and $R$ were observed. In the case of transport to the fœtus, a low flow ratio $(R \leqslant 0.6)$ led to a nearly complete equilibration between maternal arterial and fotal venous concentrations of antipyrine $\left(T_{F}: 0.7\right)$, whereas high flow ratio $(R: 1.8)$ brought about less complete equilibration $\left(T_{F}: 0.25\right)$. The reverse occurred for the transfer of antipyrine from foetus to mother. Above $R: 1.8$, the increase in flow ratio produced little or no change in transfer in either fœetal or maternal circulation.

Table 2 shows parameters $a, b$ and $r$ used to estimate the fit of our data to concurrent, countercurrent and crosscurrent models, permeability coefficient $d$ 


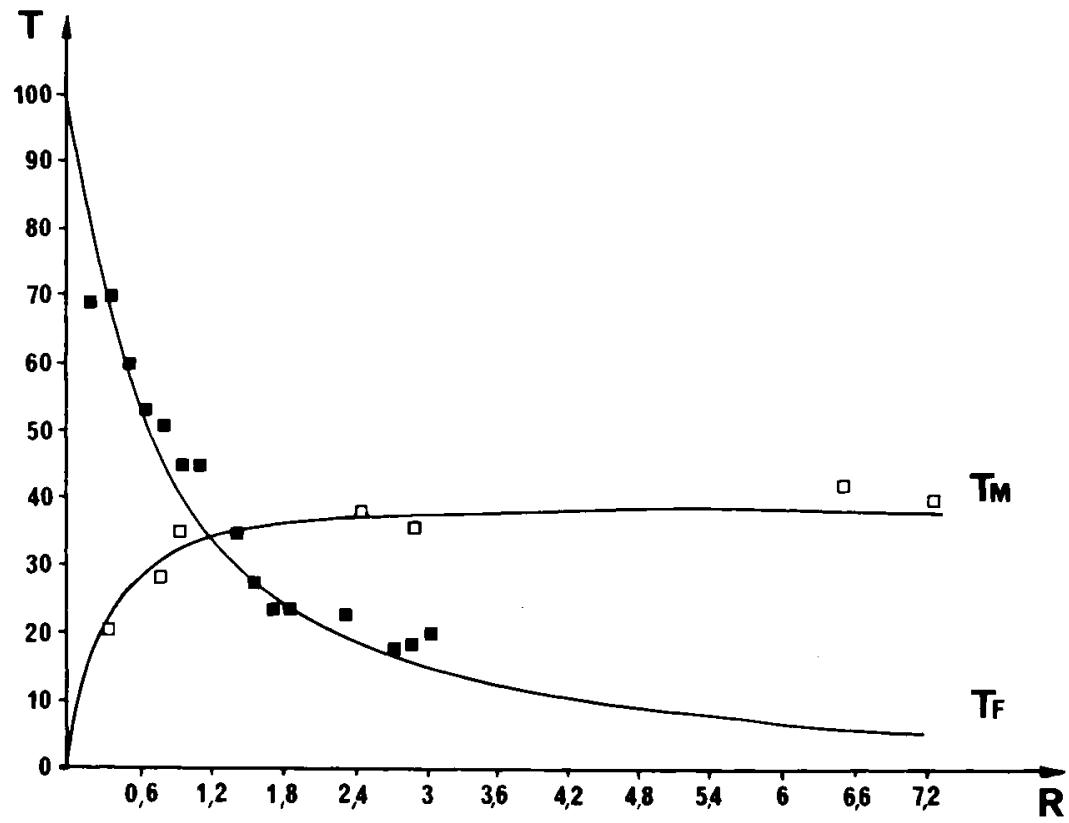

FIG. 1. - Maternal and foetal transport fractions of antipyrine in relation to perfusion flow ratio. $T_{M}, T_{F}$ and $R$ have been defined in table 1 . The theoretical lines were computed with the equation of the concurrent model.

TABLE 2

Adjustment to theoretical models, permeability coefficient and shunting.

\begin{tabular}{|c|c|c|c|c|c|c|c|c|c|c|}
\hline \multirow{2}{*}{ Exchangers } & \multicolumn{5}{|c|}{ Transfer from mother to foetus $\left(T_{F}\right)$} & \multicolumn{5}{|c|}{ Transfer from foetus to mother $\left(T_{M}\right)$} \\
\hline & a & $\mathrm{b}$ & $r$ & $\mathrm{~d}_{F}$ & $S_{F}$ & a & $\mathrm{b}$ & $r$ & $d_{M}$ & $S_{M}$ \\
\hline Countercurrent & $\begin{array}{l}0.024^{*} \\
\pm 0.017\end{array}$ & $\begin{array}{c}\$ 0.941^{*} \\
\pm 0.040\end{array}$ & 0.988 & 1.13 & 0.28 & $\begin{aligned} & 0.226^{*} \\
\pm & 0.088\end{aligned}$ & $\begin{array}{r}1.65^{*} \\
\pm 0.264\end{array}$ & 0.953 & 0.36 & -0.26 \\
\hline Crosscurrent & $\begin{array}{c}0.014^{* *} \\
\pm 0.018\end{array}$ & $\begin{array}{l}1.029^{* * *} \\
\pm 0.045\end{array}$ & 0.988 & 1.35 & 0.25 & $\begin{array}{c}0.140^{*} \\
\pm 0.032\end{array}$ & $\begin{aligned} & 0.608^{*} \\
\pm & 0.095\end{aligned}$ & 0.944 & 0.53 & 0.57 \\
\hline Concurrent & $\begin{array}{c}0.009 \\
\pm 0.022 \\
0.076^{*} \\
\pm \\
0.026\end{array}$ & $\begin{array}{c}1.019 \\
\pm 0.054 \\
1.174^{*} \\
\pm \\
0.063\end{array}$ & $\begin{array}{l}0.982 \\
0.982\end{array}$ & $\begin{array}{c}1.25 \\
\infty\end{array}$ & 0.16 & $\begin{array}{r}0.0003 \\
\pm 0.0049 \\
0.144^{*} \\
\pm 0.031\end{array}$ & $\begin{array}{c}1.002 \\
\pm 0.148 \\
0.600^{*} \\
\pm 0.092\end{array}$ & $\begin{array}{l}0.959 \\
0.959\end{array}$ & $\begin{array}{l}0.65 \\
\infty\end{array}$ & 0.13 \\
\hline
\end{tabular}

$\S$ Mean \pm standard deviation.

$a$ and $b$ are coefficients used to evaluated the fit of our experimental values to the theoretical models. Best adjustment was considered for $r=1, a=0, b=1$. As $r$ was up to 0.90 in each model, $a$ and $b$ were tested against 0 and 1 , respectively, using Student's t-test $l^{*}: p<0.001$, $\left.{ }^{* *}: p<0.01,{ }^{* * *}: p<0.05\right)$.

T : transport fraction (see table 1); d : coefficient of permeability (permeability/flow rate) ; $S$ : shunting (for calculation, see Material and methods) ; $F$ and $M$ : foetal and maternal sides, respectively. 
and extent of shunting S. Significant correlation coefficients were obtained in all models. In contrast, there was a striking difference between values $a$ and $b$ which were found closest to their theoretical value $(a=0$ and $b=1)$ in the concurrent model. Furthermore, it was the only model in which no significant difference was observed between measured and theoretical values of $a$ and $b$ at the $5 \mathrm{p}$. 100 level of significance. Thus, the concurrent model seemed to be more appropriate for describing change in transfer related to modification of flow rates in our experiments.

The $d$ coefficients obtained from $T_{F}$ and $T_{M}$ in this model were $d_{F}=1.25$ and $d_{M}=0.65$. The difference between $d_{F}$ and $d_{M}$ represented a $30 \mathrm{p} .100$ difference between $R T_{F}$ and $T_{M}$. The $d_{F}$ and $d_{M}$ values were nearly identical when $T_{M}=0.7 R T_{F}$. This might reflect variability among the perfused placentas since one series of placentas was used for measuring $T_{M}$ and another series for $T_{F}$. Because of this variability, the permeability coefficient of antipyrine must be considered to lie somewhere between 0.6 and 1.2.

The extent of shunting in the concurrent model represented $16 \mathrm{p} .100$ in the fœtal circulation and $13 \mathrm{p} .100$ in the maternal one. The hypothesis of infinite antipyrine permeability was also investigated. In that case, maternal shunting rose to $49 \mathrm{p}$. 100 . However, the significant difference $(P<0.001)$ observed in comparing measured and theoretical values of $a$ and $b$ tended to disprove this hypothesis.

\section{Discussion.}

This study confirms previous findings on the flow dependence of antipyrine placental transfer from mother to fœetus (Schneider et al., 1972). Further, it shows flow-dependent transfer of antipyrine from foetus to mother which was of smaller magnitude than that seen from mother to fœtus.

Most mammalian placentas exhibit such flow dependence for highly liposoluble compounds. However, depending on the efficiency of the placental exchanger, great differences in materno-fœtal transport fractions are observed at similar flow ratio. Transport fractions of around 80 p. 100 have been found for acetylene in rabbit (Faber and Hart, 1967) and for nitrous oxide in guinea-pig (Moll and Kastendiek, 1977) placentas for flow ratios near unity (fig. 2). The transport fractions reported for antipyrine in sheep (Meschia et al., 1966) were between 35 and 45 p. 100 at the same flow ratio. A value of 30 p. 100 was found in goat (Rankin and Peterson, 1969). An antipyrine transport fraction of around 33 p. 100 was noted in the present study on the human placenta perfused in vitro. This figure agrees well with that reported by Faber and Hart (1966) for various investigations on oxygen transport in man. Moreover, it is of the same order as that observed for antipyrine in rhesus monkey by Behrman et al. (1969) (see Faber, 1977).

The most efficient mammalian placentas (rabbit and guinea-pig) have been thought to be countercurrent exchanger types and the less efficient ones (goat and sheep) crosscurrent exchangers. The human placenta has been considered primarily a pool exchanger (Prystowski, 1957). According to Bartels and Moll 


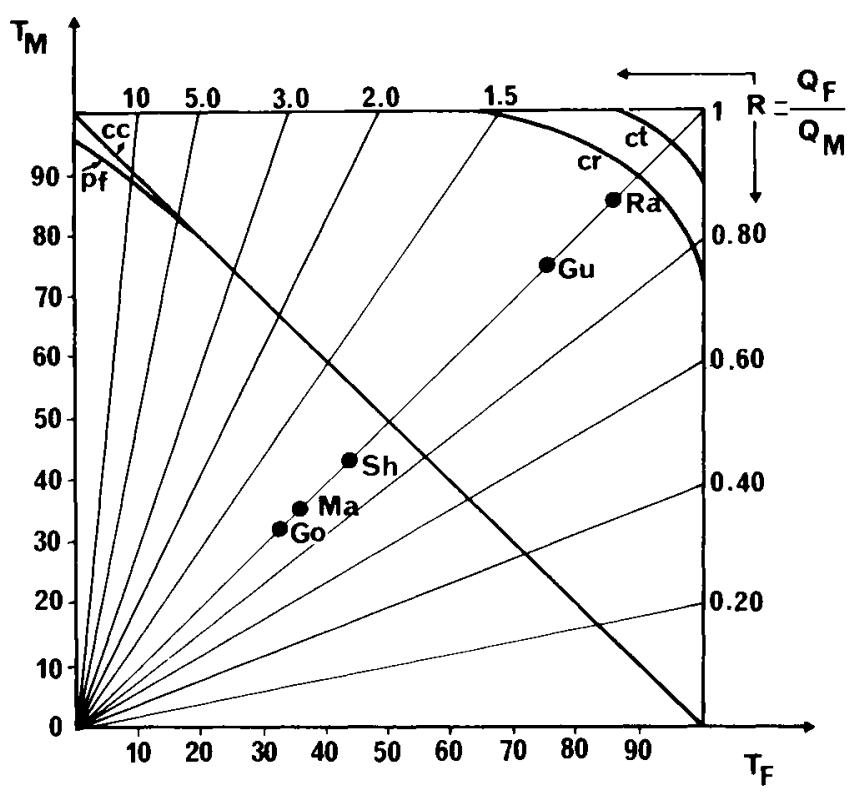

FIG. 2. - Efficiency of exchange in mammalian placentas. The theoretical T-R lines corresponding to nearly maximal permeability $(\mathrm{d}=30$ ) are presented for countercurrent (ct), crosscurrent (cr), concurrent (cc), pool flow (pf) exchangers. (-) transport fraction for $R=1$ in rabbit (Ra), guinea pig (Gu), sheep (sh), man (Ma) present study, goat (Go).

(1964) and Metcalfe et al. (1964), the vascular arrangement in humans has the character of a multivillous streambed and the exchange pattern that of a crosscurrent system. In contrast, the relationship between antipyrine transfer and the flow ratios observed in this study indicates that the human placenta behaves as the less efficient exchangers, i.e. concurrent, pool or double pool flow. It was not possible to determine which of these exchangers was involved because their pattern of exchange was very close for $d$ values as low as 0.6 and 1.2. The concurrent model was chosen arbitrarily for calculation, and it was found to fit our data well. This observation however does not implicate a concurrent arrangement in vivo where hemodynamic studies (Ramsey, 1968) suggest the presence of a mixed exchanger. Nevertheless, this model appears more appropriate than the crosscurrent or the countercurrent model for describing the change in transfer of flow-limited molecules with variations in flow rate in vitro.

These findings imply that the human placenta functions as a vein-to-vein rather than an artery-to-artery equilibrator. The umbilical and utero-placental venous concentrations of antipyrine nearly equilibrate at flow ratio close to unity. This is in contrast to guinea-pig and rabbit placentas in which equilibration of umbilical venous and utero-placental arterial concentrations of highly diffusible molecules has been reported at similar flow ratio.

Non-exchanging shunt might be responsible for the low transfer efficiency of the human placenta in vitro. Our data suggest that about $10 \%$ of the perfu- 
sion medium is diverted from the area of exchange in the foetal as well as in the maternal circulation. This figure is lower than those reported in sheep by Rankin and Peterson (1969) who found $23 \%$ for foetal shunt and $36 \%$ for maternal shunt using carbon monoxide. The extent of shunting in rhesus monkey has been estimated at about $35 \%$ in maternal circulation and about $30 \%$ in foetal circulation (Faber, 1977). Schneider et al. (1972) estimated maternal shunt of $50 \%$ on the basis of infinite antipyrine permeability. Our results suggest that this hypothesis is unacceptable. Thus, it is likely that the low efficiency of human placenta should be ascribed to the exchanger rather than to shunting. Other factors as uneven distribution of perfusion flow rates or permeability could be implicated (Faber, 1969). Their extent has not been investigated in the present study.

The existence of such shunting has not been clearly demonstrated so far in human placenta. Mayer et al. (1956) have suggested that the paravascular network constitutes the anatomical shunt in foetal circulation. This is consistent with the absence of large-diameter shunts in villous circulation reported by Penfold et al. (1981). In maternal circulation there is no anatomical support for these shunts. It is likely that shunting takes place by short-circuiting of blood flow between utero-placental artery and veins (by-passing the villi).

An interesting aspect of this study is the estimation of placental antipyrine clearance in vivo. The value of uterine blood flow rate reported by Metcalfe et al. (1955) averages $492 \mathrm{ml} / \mathrm{min}$ for a pregnant uterus weighing $5 \mathrm{~kg}$. Umbilical blood flow rate averages $248 \mathrm{ml} / \mathrm{min}$ (Stembera et al., 1965) for a foetus of $3.3 \mathrm{~kg}$. The foeto-maternal flow ratio expected from these values is 0.50 . At this ratio, transport fractions of $55 \%$ from mother to foetus and of $27 \%$ from foetus to mother were obtained on our $\mathrm{T}-\mathrm{R}$ plot. In that case, antipyrine clearance would be approximately $135 \mathrm{ml} / \mathrm{min}$ in vivo.

It has been previously shown that antipyrine and water clearances are not significantly different in perfused human placenta (Challier et al., 1977) or in sheep cotyledon (Meschia et al., 1967). The figure of antipyrine clearance estimated in the present study is about two times that observed by Hutchinson et al. (1959) for water, using compartmental analysis. Among the reasons which might explain this discrepancy are a probable underestimation of the flow ratio due to non-placental uterine blood flow, or enhanced permeability in vitro of the trophoblastic membrane due to water-filled channels (Hedley and Bradbury, 1980).

\section{Conclusion.}

This study shows a striking difference in hemochorial placentas as regards their exchange efficiency. This difference seems related to a marked species variation in the arrangement of the vascular beds. 
Résumé. Relation entre le transfert d'antipyrine et le débit circulatoire dans le placenta humain perfusé in vitro.

Le transfert placentaire de l'antipyrine, une petite molécule très liposoluble, a été étudié à différents débits circulatoires au cours de la double perfusion de lobules placentaires humains. La fraction de transfert de l'antipyrine (concentration dans la veine fœetale $x$ $100 /$ concentration dans l'artère maternelle) au rapport de débit égal à l'unité est de $33 \%$. L'efficacité d'échange du lobule perfusé in vitro est comparable à celle d'un modèle d'échange concourant présentant des shunts qui détournent $16 \%$ du débit circulatoire foetal et $13 \%$ du débit circulatoire maternel de la zone d'échange. Le coefficient de perméabilité " $d$ " de l'antipyrine dans ce modèle est compris entre 0.6 et 1.2. Ces observations sont discutées en fonction des résultats obtenus dans d'autres placentas de mammifères et dans l'espèce humaine in vivo.

\section{Références}

BARTELS H., MOLL W., 1964. Passage of inert substances and oxygen in the human placenta. Pflügers Arch., 280, 165-177.

BEHRMAN R. E., PETERSON E. N., DE LANNOY C. W., 1969. The supply of $\mathrm{O}_{2}$ to the primate fetus with two different $\mathrm{O}_{2}$ tensions and anesthesics. Resp. Physiol., 6, 271-283.

CHALLIER J. C., GUERRE-MILLO M., RICHARD M. O., SCHNEIDER H., PANIGEL M., OLIVE G, 1977. Transfert et échange d'antipyrine dans le lobule placentaire humain perfusé in vitro. Ann. Biol. anim. Bioch. Biophys., 17, 1107-1115.

CHALLIER J. C., MILLO-GUERRE M., NANDAKUMARAN M., OLIVE G., PANIGEL M., 1977. Placental transfer in vitro of water, antipyrine and inulin. Proc. int. Un. Physiol. Sci, $27^{\mathrm{e}}$ Congr., Vol. XIII, p. 129.

FABER J. J., 1969. Application of the theory of heat exchangers to the transfer of inert materials in placentas. Circulat. Res., 24, 221-234.

FABER J. J., 1977. Steady state methods for the study of placental exchange. Fed. Proc., 36, 2640-2646.

FABER J. J., HART F. M., 1966. The rabbit as an organ of diffusional exchange. Comparison with other species by dimensional analysis. Circulat. Res., 19, 816-833.

FABER J. J., HART F. M., 1967. Transfer of charged and uncharged molecules in the placenta of the rabbit. Amer. J. Physiol., 213, 890-894.

HEDLEY R., BRADBURY M. W. B., 1980. Transport of polar non-electrolytes across the intact and perfused guinea pig placenta. Placenta, 1, 277-285.

HUTCHINSON D. L., GRAY M. J., PLENTL A. A., ALVAREZ H., CALDEYRO-BARCIA R., KAPLAN B., LIND J., 1959. The role of the foetus in the water exchange of the amniotic fluid of normal and hydramniotic patients. J. clin. Invest., 38, 971-980.

MAYER M., PANIGEL M., LECLERC-POLYAK H., 1956. Observations sur l'aspect et la disposition des vaisseaux et des capillaires fœtaux dans le placenta humain. Gynec. Obstet., 55, 257280.

MESCHIA G., BATTAGLIA F. C., BRUNS P. D., 1967. Theoretical and experimental study of transplacental diffusion. J. appl. Physiol., 22, 1171-1178.

MESCHIA G., COTTER J. R., MAKOWSKI E. L., BARRON D. H., 1966. Simultaneous measurement of uterine and umbilical blood flows and oxygen uptakes. Quart. J. exp. Physiol., 52, $1-18$.

METCALFE J., ROMNEY S. L., RAMSEY L. M., REID D. E., BURWELL C. S., 1955. Estimation of uterine blood flow in normal human pregnancy at term. J. clin. Invest., 34, 1632-1638.

METCALFE J., MOLL W., BARTELS H., 1964. Gas exchange across the placenta. Fed. Proc., 23, 774-780.

MOLL W., KASTENDIECK E., 1977. Transfer of $\mathrm{NO}_{2}, \mathrm{CO}$ and $\mathrm{HTO}$ in the artificially perfused guinea-pig placenta. Resp. Physiol., 29, 283-302.

PENFOLD P., WOOTON R., HYTTEN F. E., 1981. Studies of single placental cotyledon in vitro : III. The dimensions of the villous capillaries. Placenta, 2, 161-168. 
PRYSTOWSKI H., 1957. Fetal blood studies. VII the oxygen pressure gradient between the maternal and fetal bloods of the human in normal and abnormal pregnancy. Bull. Johns Hopk. Hosp., 101, 48-56.

RAMSEY E. M., 1968. Uteroplacental circulation during labor. Clin. obstet. Gynec., 11, 78-95.

RANKIN J. H. G., PETERSON E. N., 1969. Application of the theory of heat exchangers to a physiological study of the goat placenta. Circulat. Res., 24, 235-250.

SCHNEIDER H., PANIGEL M., DANCIS J., 1972. Transfer across the perfused human placenta of antipyrine sodium and leucine. Amer. J. Obstet. Gynec., 114, 822-828.

STEMBERA Z. K., HODR J., JADA J., 1965. Umbilical blood flow in healthy newborn infants during the first minutes after birth. Amer. J. Obset. Gynec., 91, 568-574. 